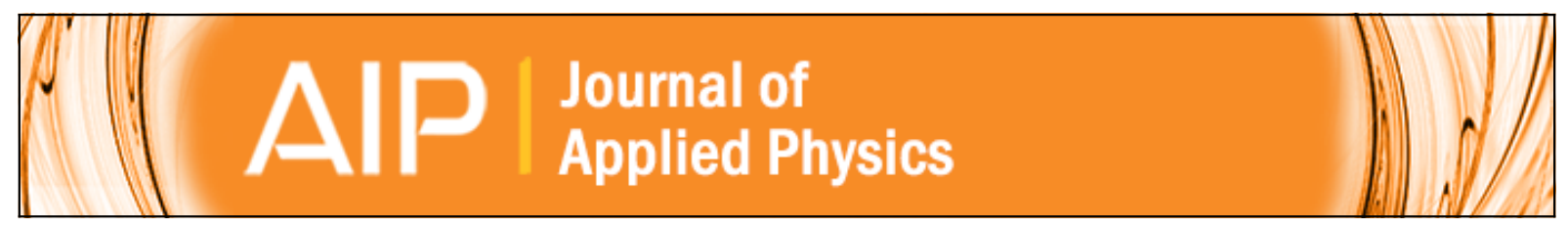

\title{
Giant magnetoelectric effect in sintered multilayered composite structures
}

Rashed A. Islam, Yong Ni, Armen G. Khachaturyan, and Shashank Priya

Citation: Journal of Applied Physics 104, 044103 (2008); doi: 10.1063/1.2966597

View online: http://dx.doi.org/10.1063/1.2966597

View Table of Contents: http://scitation.aip.org/content/aip/journal/jap/104/4?ver=pdfcov

Published by the AIP Publishing

\section{Articles you may be interested in}

Reduced leakage current and improved ferroelectricity in magneto-electric composite ceramics prepared with microwave assisted radiant hybrid sintering

AlP Advances 5, 047135 (2015); 10.1063/1.4919097

Giant self-biased magnetoelectric response with obvious hysteresis in layered homogeneous composites of negative magnetostrictive material Samfenol and piezoelectric ceramics

Appl. Phys. Lett. 103, 202902 (2013); 10.1063/1.4829634

Effect of $\mathrm{B} 2 \mathrm{O} 3-\mathrm{Bi} 2 \mathrm{O} 3-\mathrm{SiO} 2-\mathrm{ZnO}$ glass on the dielectric and magnetic properties of ferroelectric/ferromagnetic composite for low temperature cofired ceramic technology

J. Appl. Phys. 107, 09D911 (2010); 10.1063/1.3360347

Magnetic field anomaly detector using magnetoelectric composites

J. Appl. Phys. 101, 024108 (2007); 10.1063/1.2427095

Effect of composition on coupled electric, magnetic, and dielectric properties of two phase particulate magnetoelectric composite

J. Appl. Phys. 101, 014109 (2007); 10.1063/1.2404773

MIT LINCOLN

LABORATORY

CAREERS

Discover the satisfaction of innovation and service

to the nation
- Space Control

- Air \& Missile Defense

- Communications Systems \& Cyber Security

- Intelligence, Surveillance and

Reconnaissance Systems
- Advanced

Electronics

- Tactical Systems

- Homeland

Protection

- Air Traffic Control

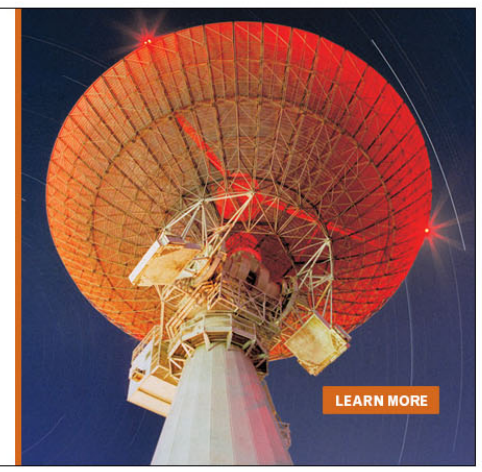




\title{
Giant magnetoelectric effect in sintered multilayered composite structures
}

\author{
Rashed A. Islam, ${ }^{1}$ Yong Ni, ${ }^{2}$ Armen G. Khachaturyan, ${ }^{2}$ and Shashank Priya ${ }^{3, a)}$ \\ ${ }^{1}$ Department of Materials Science and Engineering, UT Arlington, Arlington, Texas 76019, USA \\ ${ }^{2}$ Department of Materials Science and Engineering, Rutgers University, Piscataway, New Jersey 08854, \\ USA \\ ${ }^{3}$ Department of Materials Science and Engineering, Virginia Tech, Blacksburg, Virginia 24061, USA
}

(Received 7 May 2008; accepted 11 June 2008; published online 19 August 2008)

\begin{abstract}
Trilayer composites consisting of $0.9 \mathrm{~Pb}\left(\mathrm{Zr}_{0.52} \mathrm{Ti}_{0.48}\right) \mathrm{O}_{3}-0.1 \mathrm{~Pb}\left(\mathrm{Zn}_{1 / 3} \mathrm{Nb}_{2 / 3}\right) \mathrm{O}_{3}(0.9 \mathrm{PZT}-0.1 \mathrm{PZN})$ and $\mathrm{Ni}_{0.6} \mathrm{Cu}_{0.2} \mathrm{Zn}_{0.2} \mathrm{Fe}_{2} \mathrm{O}_{4}$ (NCZF) in the configuration NCZF-(0.9 PZT-0.1 PZN)-NCZF were synthesized using pressure assisted sintering. Composites with optimized magnetostrictive to piezoelectric thickness ratio showed a high magnetoelectric (ME) coefficient of $525 \mathrm{mV} / \mathrm{cm}$ Oe. Further enhancement in the magnitude of ME coefficient was obtained $(595 \mathrm{mV} / \mathrm{cm} \mathrm{Oe})$ when the angle of applied dc magnetic field was changed to $45^{\circ}$. Changing the intermediate piezoelectric layer from single to trilayer stack geometry configuration leads to the realization of giant $\mathrm{ME}$ response of $782 \mathrm{mV} / \mathrm{cm}$ Oe in sintered composites. (C) 2008 American Institute of Physics. [DOI: $10.1063 / 1.2966597]$
\end{abstract}

\section{INTRODUCTION}

Magnetoelectric (ME) particulate composites combine the magnetostrictive and piezoelectric properties of materials $^{1-3}$ through the product property of the system. ${ }^{4}$ Compared to in situ composite synthesized by unidirectional solidification of $\mathrm{BaTiO}_{3}-\mathrm{CoFe}_{2} \mathrm{O}_{4},{ }^{5-8}$ sintered particulate composite is advantageous because of its cost effectiveness, easy fabrication process, and better control of the process parameters. On the other hand laminated ME composites synthesized by using piezoelectric and magnetostrictive materials have gained attention because they exhibit superior $\mathrm{ME}$ response. The laminates are generally fabricated by sandwiching and bonding piezoelectric plate/disk/fibers between two layers of magnetostrictive plates/disks/foils. ${ }^{9-15}$ Sintered particulate composites show inferior properties compared to laminated composites because of the drawbacks such as low resistivity, interface defects, interface diffusion, mismatch in elastic compliance, and degradation in individual material parameters. Previously, we have shown that soft piezoelectric phase (high dielectric and piezoelectric constant), soft magnetic phase (high permeability and low coercivity), large piezoelectric grain size $(>1 \mu \mathrm{m})$, layered structure, and postsintering thermal treatment (annealing and aging) lead to the enhancement in magnitude of $\mathrm{ME}$ coefficient. $^{16-21}$ In this study, we combine the advantages of layered composite with that of sintering process and investigate the geometrical and microstructural parameters that can further enhance the performance of sintered $\mathrm{ME}$ composites.

\section{EXPERIMENTAL}

Previously, we have shown that pressure assisted sintering can provide trilayer composites with any desired dimensions. Further, we have reported the compositions such that sintering can be performed at low temperature of $900{ }^{\circ} \mathrm{C}$, which results in stable electrodes. In this study, we investi-

a)Electronic mail: spriya@vt.edu. gate the effect of piezoelectric layer thickness in trilayer sintered $\mathrm{ME}$ composite upon the $\mathrm{ME}$ coupling. Powders of $0.9 \mathrm{~Pb}\left(\mathrm{Zr}_{0.52} \mathrm{Ti}_{0.48}\right) \mathrm{O}_{3}-0.1 \mathrm{~Pb}\left(\mathrm{Zn}_{1 / 3} \mathrm{Nb}_{2 / 3}\right) \mathrm{O}_{3}$ (PZT-PZN) and $\mathrm{Ni}_{0.6} \mathrm{Cu}_{0.2} \mathrm{Zn}_{0.2} \mathrm{Fe}_{2} \mathrm{O}_{4}$ (NCZF) were synthesized using conventional mixed oxide method and trilayers were synthesized using the process described elsewhere. ${ }^{22}$

In order to experimentally investigate the effect of thickness ratio and achieve a higher ME coefficient, composites of different piezoelectric thicknesses were synthesized. NCZF composition was used as the magnetostrictive layer and PZT-PZN composition was used as the piezoelectric layer. The amount of NCZF was fixed at $0.7 \mathrm{~g}$ for top and bottom layers, whereas the weight of PZT-PZN was varied from 0.8 to $0.3 \mathrm{~g}$. The interface electrode used in this study was Dupont $6160 \mathrm{Ag}-\mathrm{Pd}$ conductor paste. The sintering was done at $900{ }^{\circ} \mathrm{C}$ for $3 \mathrm{~h}$ using a load of $450 \mathrm{~g}$, which is equivalent to $50 \mathrm{kPa}$. After sintering each composite was cross sectioned and polished for scanning electron microscopy. Figure 1(a) shows the cross sections of trilayer composite. The thickness of interface electrode observed in these composites was in the range of 5-10 $\mu \mathrm{m}$. The adherence of interface electrode with PZT-PZN and NCZF was found to be good. The PZT-PZN grain size observed in all the composites was above $1 \mu \mathrm{m}$. X-ray elemental analysis was performed using the scanning electron microscope in order to identify any elemental diffusion through the electroded interface. Figures 1(b)-1(d) show the elemental analysis of $\mathrm{Pb}$, $\mathrm{Fe}$, and $\mathrm{Ag}$. A strong concentration of $\mathrm{Pb}$ was found on the PZT-PZN side and Fe on the NCZF side. Ag was found to be concentrated in the center region. By adding this interface electrode the piezoelectric property was improved from 80 $\mathrm{pC} / \mathrm{N}$ for cofired bilayer to $225 \mathrm{pC} / \mathrm{N}$ for trilayer composite.

ME coefficient $(d E / d H)$ was determined by applying an ac magnetic field at $1 \mathrm{kHz}$ and 1 Oe amplitude $(H)$ under varying dc magnetic bias. The ac magnetic field was generated by a Helmholtz coil powered by Agilent 3320 function generator. The output voltage generated from the composite was measured using a SRS DSP lock-in amplifier (model SR 

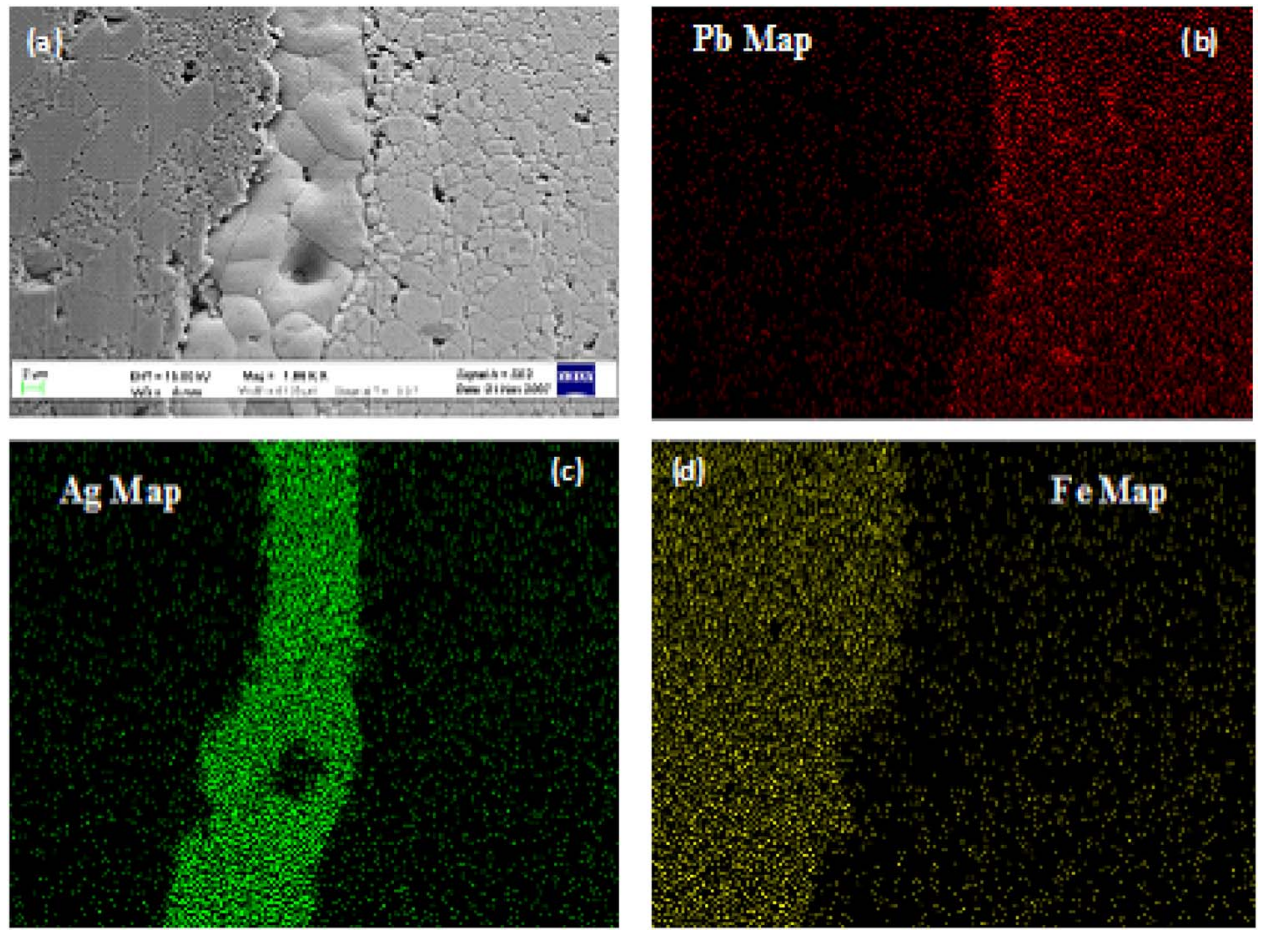

830). The ME coefficient ( $\mathrm{mV} / \mathrm{cm} \mathrm{Oe}$ ) was calculated by dividing the measured output voltage by thickness of the sample and applied ac magnetic field.

\section{RESULTS AND DISCUSSION}

The thickness ratio plays an important role in trilayer ME composites. Using the expression derived by Srinivasan et $a .^{23}$ it can be shown that the ME coefficient depends on piezoelectric coefficient $\left(d_{31}\right)$, permittivity $\left(\varepsilon_{33}\right)$, elastic com- pliance $\left(s_{11}\right.$ and $\left.s_{12}\right)$, thickness $\left(t_{P}\right)$ of the piezoelectric phase, piezomagnetic coefficient $\left(q_{11}\right)$, elastic compliance $\left(s_{11}\right.$ and $s_{12}$ ), and thickness $\left(t_{m}\right)$ of the magnetic phase as the following:
FIG. 1. (Color online) X-ray elemental mapping of trilayer sample, (a) image of trilayer sample, (b) $\mathrm{Pb}$ map, (c) Ag map, and (d) Fe map.
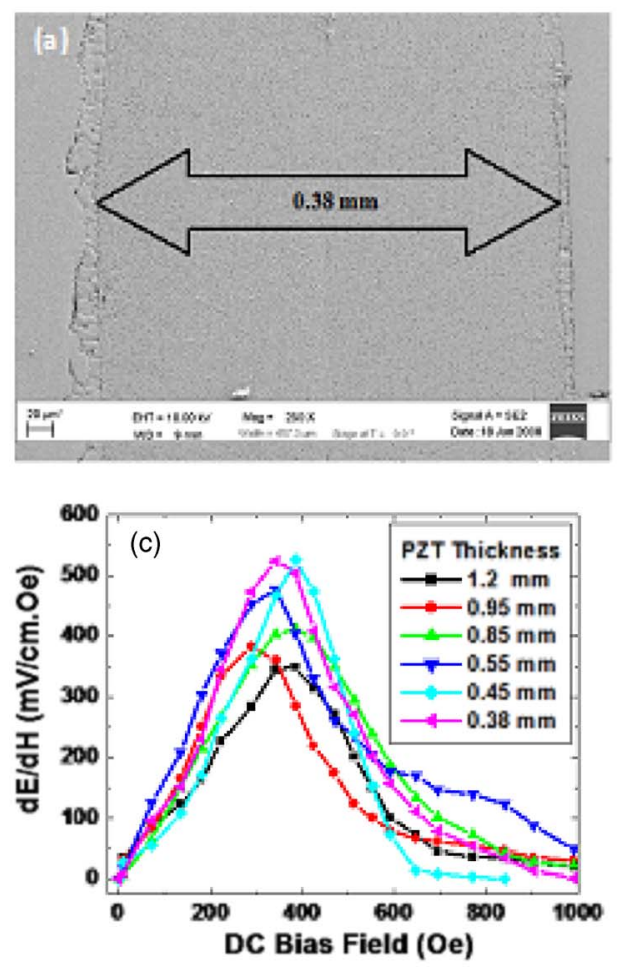
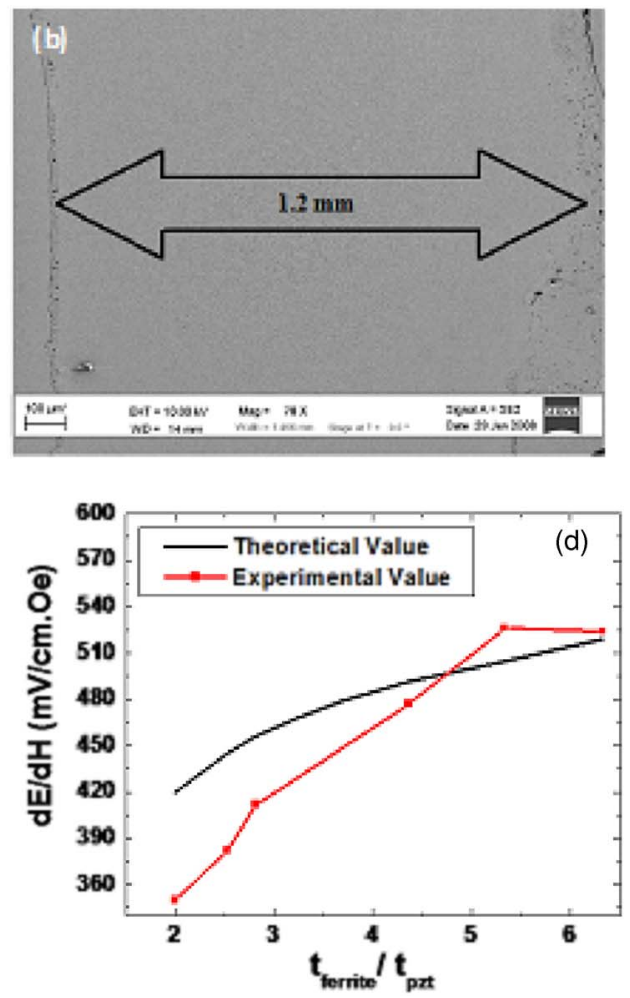

FIG. 2. (Color online) (a) Trilayer composite with piezoelectric layer thickness of $0.38 \mathrm{~mm}$, (b) trilayer composite with piezoelectric layer thickness of $1.2 \mathrm{~mm}$, (c) ME coefficient as a function of dc bias field for different thicknesses of piezoelectric layer, and (d) comparison between theoretical and experimental ME coefficients for different thickness ratios of magnetic to piezoelectric layer. 

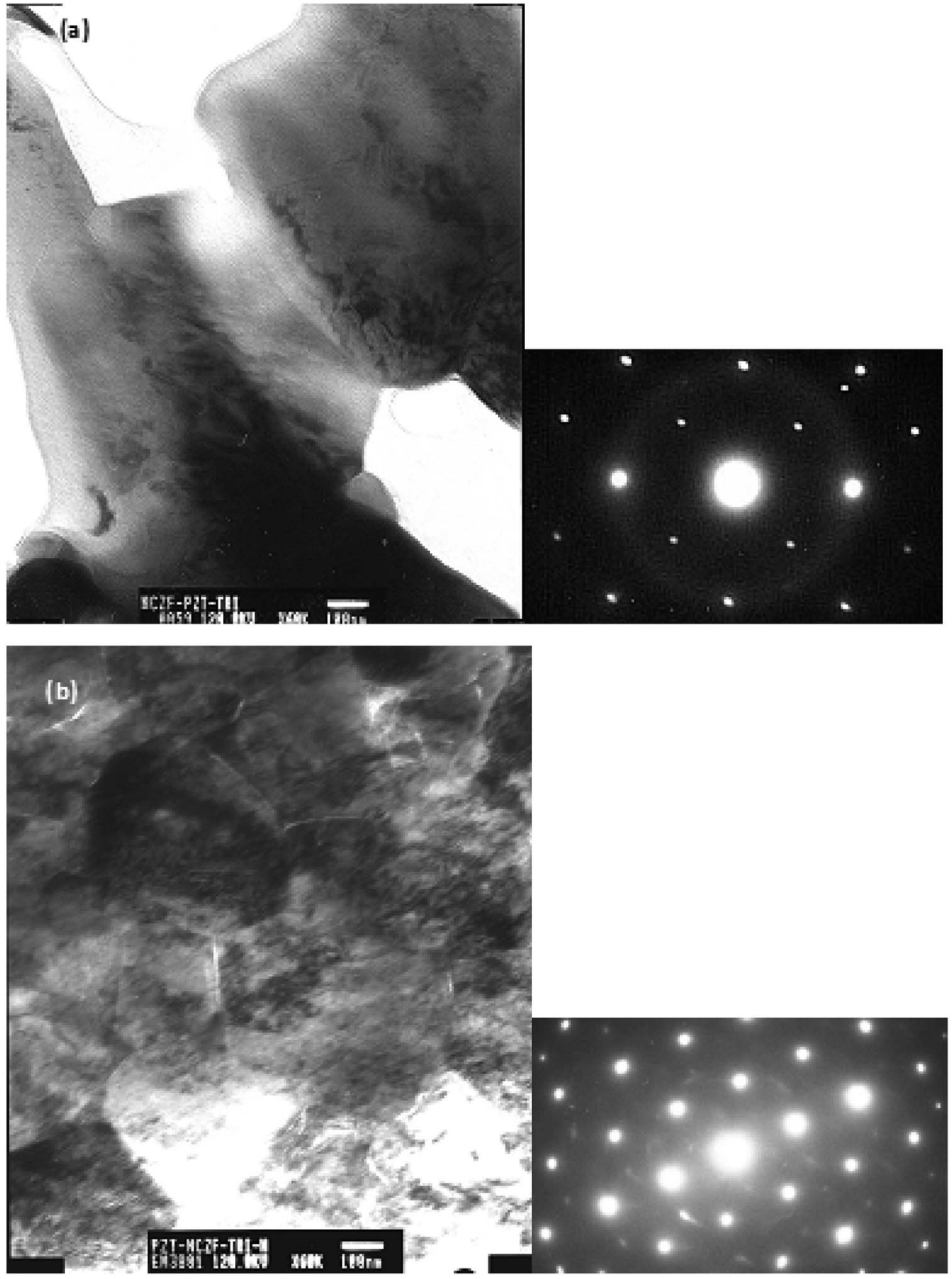

FIG. 3. TEM micrograph and SAED pattern for (a) PZT-PZN and (b) NCZF near the interface in trilayer composites.
Equation (1) shows that ME coefficient is a function of magnetostrictive to piezoelectric layer thickness ratio. Figures 2(a) and 2(b) show the cross-section image of trilayer composite with different thicknesses of the piezoelectric phase. Figure 2(c) shows the ME coefficient as a function of dc bias field for different thicknesses of piezoelectric layer. It was found that as the thickness ratio of magnetic layer to piezoelectric layer increases (thickness of piezoelectric layer decreases as the magnetic layer thickness was fixed) ME coefficient increases from 354 to $526 \mathrm{mV} / \mathrm{cm} \mathrm{Oe.} \mathrm{The}$ maximum ME coefficient of $526 \mathrm{mV} / \mathrm{cm}$ Oe was found when the thickness ratio was 5.3 (piezoelectric layer thickness was $0.45 \mathrm{~mm}$ ).

The calculated theoretical magnitude of ME coefficient using Eq. (1) is plotted along with the experimental values in Fig. 2(d). The experimental values were found to have close resemblance with the prediction from theory. The ME coef- ficient was of the order of $350 \mathrm{mV} / \mathrm{cm}$ Oe for piezoelectric layer thickness of $1.2 \mathrm{~mm}$ (ratio of 2) and it increases as the ratio increases. The increase in $\mathrm{ME}$ coefficient and the decrease in piezoelectric layer thickness can be explained in terms of increased compressive stress on piezoelectric layer.

Ryu et $a .^{3}$ have shown that the compressive and tensile stresses in piezoelectric and ferrite layers can be calculated using the beam theory given as

$$
\begin{aligned}
\sigma_{31 f}^{E} & =\frac{E_{f} E_{p} t_{p} \Delta \varepsilon_{o}}{(1-\gamma)\left(2 E_{f} t_{f}+E_{p} t_{p}\right)}, \\
\sigma_{31 p}^{E} & =-\frac{2 E_{f} E_{p} t_{p} \Delta \varepsilon_{o}}{(1-\gamma)\left(2 E_{f} t_{f}+E_{p} t_{p}\right)} .
\end{aligned}
$$

As the thickness of ferrite layer remains the same $(1.2 \mathrm{~mm}$ on top and bottom), the compressive stress on piezoelectric 

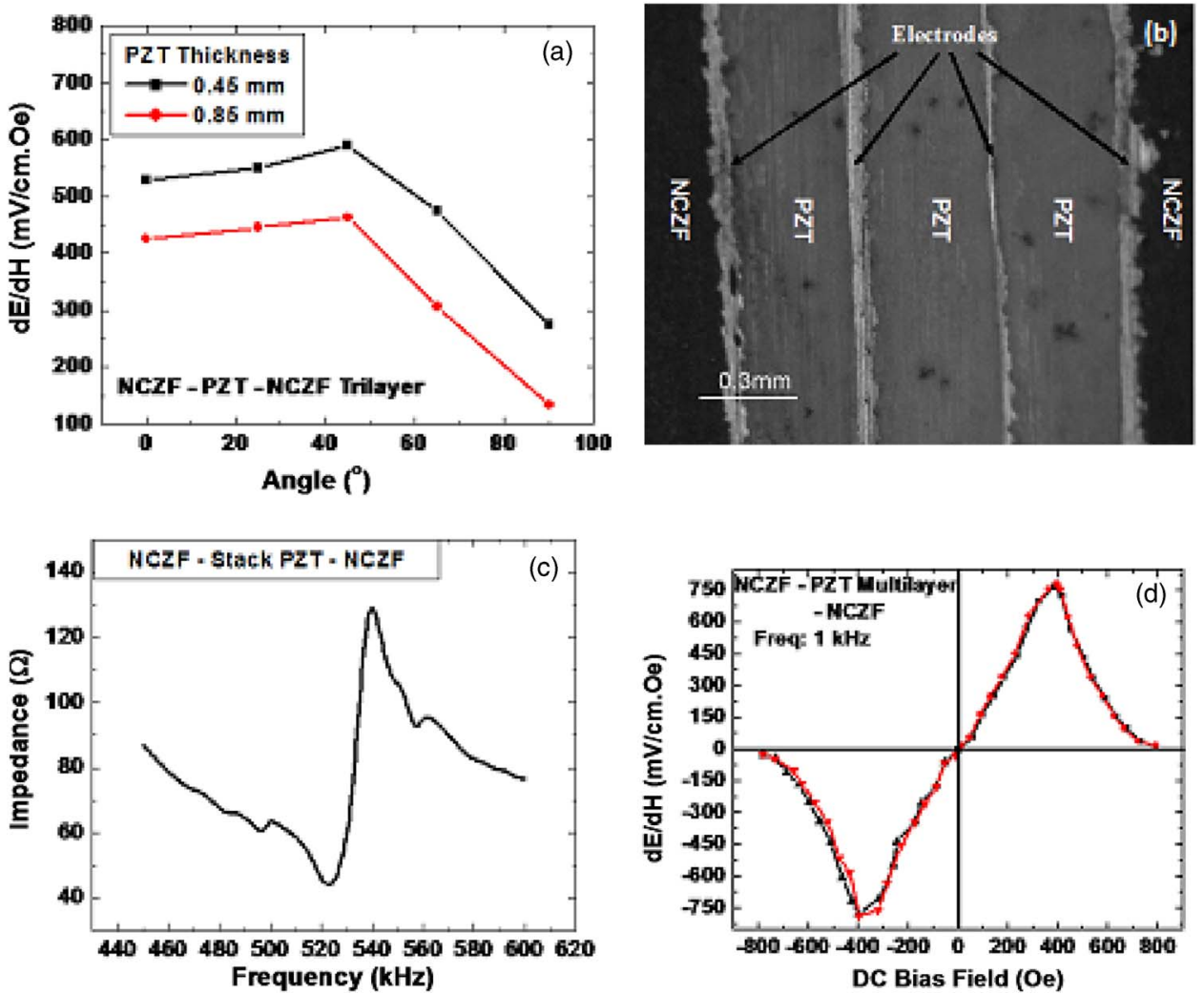

layer can be increased if the thickness of piezoelectric layer is decreased. The compressive stress is related to ME coefficient as $^{3}$

$$
\frac{d E}{d H}=\frac{2 g_{31} \sigma_{31 P}^{E}}{H_{\mathrm{ac}}} .
$$

Thus, as the compressive stress in piezoelectric is increased, ME coefficient increases.

Figures 3(a) and 3(b) show the transmission electron microscopy (TEM) micrographs of PZT-PZN and NCZF phases close to the interface. The inset of each image shows the selected area electron diffraction (SAED) pattern. The micrographs were taken within $10 \mu \mathrm{m}$ from the interface on both sides. From the diffraction pattern, pure piezoelectric and magnetic phases can be identified. The grain sizes observed in these micrographs were around $1 \mu \mathrm{m}$ for piezoelectric phase and $\sim 500 \mathrm{~nm}$ for NCZF phases. The lattice parameters calculated from SAED pattern were found to be $a$ $=4.04 \AA$ and $c=4.11 \AA$ with tetragonality $(c / a$ ratio) of 1.017. The lattice constant for NCZF was calculated to be $8.41 \AA$. This clearly signifies that the interface diffusion was limited in the trilayer. The interface diffusion length observed in the case of bilayer composite was around $30 \mu \mathrm{m}$, which did not consist of intermediate electrode. Thus, trilayer geometry with intermediate electrode layer was able to reduce the interface diffusion.

Figure 4(a) shows the magnetic field (ac and dc) orientation dependence of ME coefficient for trilayer composite (piezoelectric layer thicknesses of 0.45 and $0.85 \mathrm{~mm}$ ). It was found that the composite shows an increase in ME coefficient from $0^{\circ}$ (when magnetic field direction is parallel to the sample surface) to $45^{\circ}$. The maximum ME coefficients of
589 and $463 \mathrm{mV} / \mathrm{cm}$ Oe were measured at $45^{\circ}$ orientation. As the angle is increased beyond $45^{\circ}$, the ME coefficient starts to drop rapidly and when the sample surface is perpendicular to the magnetic field direction (T-T mode), low values of 274 and $134 \mathrm{mV} / \mathrm{cm}$ Oe were observed for two different thicknesses of piezoelectric layer. It has been shown that with areal angle change, the strain of the magnetic phase changes and is maximum around $51^{\circ} .{ }^{24}$ As the strain increases compressive stress on piezoelectric layer also increases, which contributes to the high ME coefficient as expressed by Eq. (4). At $90^{\circ}$ angle the ME coefficient was found to have low magnitude.

In trilayer ME composite based on NCZF-(PZT-PZN)NCZF composition, the optimum magnitude of $d_{33}$ and dielectric constant were found to be $225 \mathrm{pC} / \mathrm{N}$ and 1150. In order to achieve higher piezoelectric and dielectric constants, it is necessary to change the electrode pattern of the piezoelectric layer. Thus, a stack actuator configuration was implemented in trilayer geometry as intermediate layer between two NCZF layers. Figure 4(b) shows the optical image of new trilayer design with stacked PZT-PZN configuration. It can be seen from this figure that instead of single PZT-PZN layer there were three PZT-PZN layers and corresponding interdigital electrode layers along thickness direction. The sintering temperature and time were $900{ }^{\circ} \mathrm{C}$ for $3 \mathrm{~h}$ with very slow heating and cooling rates $\left(\sim 1{ }^{\circ} \mathrm{C} / \mathrm{min}\right)$. Pressure applied during the sintering was $50 \mathrm{kPa}$ to avoid any delamination. It was found that each layer of PZT-PZN was around $300 \mu \mathrm{m}$ combined with a thickness of $0.9 \mathrm{~mm}$. NCZF layers were found to have a thickness of $1.2 \mathrm{~mm}$.

In the above configuration, piezoelectric constant $\left(d_{33}\right)$ increased from 204 to $535 \mathrm{pC} / \mathrm{N}$ and dielectric constant from 
1132 to 5500. However, the dielectric loss of stack PZT-PZN increased from $5 \%$ to $13.4 \%$, which may be due to incomplete sintering of $\mathrm{Ag}-\mathrm{Pd}$ electrode and PZT-PZN. The increase in electromechanical coupling constant from 0.14 to 0.21 was observed, which indicates that there was minimal mechanical defect in the fabricated structure. Figure 4(c) shows the impedance spectrum of trilayer ME composite. The resonance frequency was measured to be $523 \mathrm{kHz}$, which is higher than that of single layer PZT-PZN and shows resonance at $258 \mathrm{kHz}$ for the same dimensions. Also the bandwidth (difference between resonance and antiresonance) was found to be higher $(17 \mathrm{kHz})$ in the case of trilayer composite with stack actuator configuration.

Figure 4(d) shows the ME coefficient of stack PZT-PZN based trilayer composite. It shows a peak coefficient of $782 \mathrm{mV} / \mathrm{cm}$ Oe at 400 Oe magnetic dc bias. In order to check whether there is any hysteresis behavior, the ME coefficient was measured from negative to positive high field and vice versa. It was found that there is very small hysteresis in the response. Compared to the single layer PZT-PZN in trilayer configuration $(412 \mathrm{mV} / \mathrm{cm} \mathrm{Oe})$, stack PZT-PZN shows much higher ME coefficient. This is a significant improvement in the performance of the sintered ME composites.

\section{SUMMARY}

NCZF-(0.9 PZT-0.1 PZN)-NCZF trilayer was fabricated using pressure assisted sintering. Optimization of ferrite to PZT-PZN layer thickness was done in order to find the most favorable thickness ratio. It was found that for PZT-PZN layer thickness of $0.45 \mathrm{~mm}$ (ferrite to PZT-PZN thickness ratio of 5.33) the $\mathrm{ME}$ coefficient increases from 412 (for PZT-PZN thickness 0.85 ) to $526 \mathrm{mV} / \mathrm{cm}$ Oe. Optimization of magnetic field orientation measurement shows that if the angle between the magnetic field direction and the sample surface is $45^{\circ}$, the $\mathrm{ME}$ coefficient magnitude reaches $589 \mathrm{mV} / \mathrm{cm}$ Oe (for $0.45 \mathrm{~mm}$ PZT thickness). Instead of a single PZT-PZN layer if a stack configuration was adopted, a significant improvement in ME coefficient was obtained.

\section{ACKNOWLEDGMENTS}

The authors gratefully acknowledge the financial support from Office of Basic Energy Sciences, Department of Energy. The authors (R.I. and S.P.) would also like to acknowledge the support from Army Research Office.

${ }^{1}$ J. Van Suchetelene, Philips Res. Rep. 27, 28 (1972).

${ }^{2}$ J. Ryu, S. Priya, K. Uchino, D. Viehland, and H. Kim, J. Kor. Ceram. Soc. 39, 813 (2002).

${ }^{3}$ J. Ryu, S. Priya, and K. Uchino, J. Electroceram. 8, 107 (2002).

${ }^{4}$ G. R. Harshe, Ph.D. thesis, Pennsylvania State University, 1991.

${ }^{5}$ J. V. D. Boomgaard and R. A. J. Born, J. Mater. Sci. 13, 1538 (1978).

${ }^{6}$ J. V. D. Boomgaard, D. R. Terrell, R. A. J. Born, and H. F. J. I. Giller, J. Mater. Sci. 9, 1705 (1974)

${ }^{7}$ A. M. J. G. Van Run, D. R. Terrell, and J. H. Scholing, J. Mater. Sci. 9, 1710 (1974).

${ }^{8}$ J. V. D. Boomgaard, A. M. J. G. Van Run, and J. Van Suchtelen, Ferroelectrics 10, 295 (1976).

${ }^{9}$ S. Dong, J. Li, and D. Viehland, Appl. Phys. Lett. 83, 2265 (2003).

${ }^{10}$ S. Dong, J. Zhai, J. Li, and D. Viehland, Appl. Phys. Lett. 89, 252904 (2006).

${ }^{11}$ G. Srinivasan and Y. K. Fetisov, Ferroelectrics 342, 65 (2006).

${ }^{12}$ R. Zhang, M. Wang, N. Zhang, and G. Srinivasan, Acta Phys. Sin. 55, 2548 (2006).

${ }^{13}$ Z. Shi, J. Ma, Y. H. Lin, and C. W. Nan, J. Appl. Phys. 101, 043902 (2007).

${ }^{14}$ S. Dong, J. Zhai, J. F. Li, D. Viehland, and M. I. Bichurin, Appl. Phys. Lett. 89, 243512 (2006).

${ }^{15}$ D. A. Filippov, M. I. Bichurin, C. W. Nan, and J. M. Liu, J. Appl. Phys. 97, 113910 (2005).

${ }^{16}$ R. A. Islam and S. Priya, Integr. Ferroelectr. 82, 1 (2006).

${ }^{17}$ R. A. Islam and S. Priya, Jpn. J. Appl. Phys., Part 2 45, L128 (2006).

${ }^{18}$ R. A. Islam and S. Priya, Int. J. Appl. Ceram. Technol. 3, 353 (2006).

${ }^{19}$ R. A. Islam, D. Viehland, and S. Priya, J. Mater. Sci. Lett. 43, 1497 (2008).

${ }^{20}$ R. A. Islam, and S. Priya, J. Mater. Sci. 43, 3560 (2008).

${ }^{21}$ R. A. Islam, J. C. Jiang, S. Priya, F. Bai, and D. Viehland, Appl. Phys. Lett. 91, 162905 (2007).

${ }^{22}$ R. A. Islam and S. Priya, J. Mater. Sci. 43, 2072 (2008).

${ }^{23}$ G. Srinivasan, E. Rasmussen, J. Gallegos, R. Srinivasan, Y. I. Bokhan, and V. M. Laletin, Phys. Rev. B 64, 214408 (2001).

${ }^{24}$ J. Ryu, S. Priya, A. V. Carazo, K. Uchino, and H. Kim, J. Am. Ceram. Soc. 84, 2905 (2001). 